\title{
EL ESTADO NEOLIBERAL COMO DETONANTE DE LA CRISIS DE VIOLENCIA
}

\section{THE NEOLIBERAL STATE AS A TRIGGER OF VIOLENCE CRISIS}

\author{
Lic. Wael Sarwat Hikal Carreón \\ Universidad Autónoma de Nuevo León \\ ORCID: 0000-0003-1278-567X \\ wshc1983.2013@gmail.com \\ México
}

\section{SUMARIO}

- Introducción

- El desorden social como detonante de la crisis violenta. Durkheim

- Conflicto entre metas y medios. Parsons

- El estado como tutor de la represión, desigualdad y violencia: Spencer, Weber y Bourdieu

- Conclusiones

- Fuentes de Información

\section{RESUMEN}

El presente ensayo expone la revisión teórica de cinco autores cuyos estudios se dirigieron a la comprensión de la dinámica social, los fenómenos que surgen en las sociedades, que transforman para mal la interacción entre los individuos, la industria $\mathrm{y}$ el estado, teniendo conflictos entre las metas de vida y medios de obtención, debido a una desigualdad social cada vez más perpetuada por quienes tienen el poder, en específico el Estado y la empresa, donde estas consolidan marcadas diferencias entre grupos, presionando hacia la desorganización, incertidumbre económica, política, social, de estabilidad, entre otras, provocando panoramas inciertos que llevan a los sujetos a modos de expresión de la violencia derivado del desacuerdo con las imposiciones del Estado y la industria, teniendo este que implementar el monopolio de la violencia para contener las reacciones de grupos divergentes. De los autores con mayor resonancia en el tema del desorden social, se encuentra Durkheim.

Por su parte, Parsons, señala esa distancia entre metas y medios y el conflicto que produce. Otro que se abordan es Spencer, que puntualiza sobre los conflictos entre grupos ante la represión del Estado. Weber explica la consolidación del aparato del Estado mediante recaudación de dinero y establecimiento de sus aparatos de control. Finalmente, Bourdieu se refiere a las formas neoliberales que distancian a los sujetos de las oportunidades y apoyo que el Estado podría dar, relegándolo a su suerte.

\begin{abstract}
This present essay exposes the theoretical review of five authors whose studies focused on understanding the social dynamics, the phenomena that arise in societies, which transform for the worse the interaction between individuals, industry and the state, taking conflicts between life goals and means of obtaining, due to a social inequality increasingly perpetuated by those in power, specifically the state and the company, where they consolidate marked differences between groups, pushing towards disorganization, economic
\end{abstract}


uncertainty, political, social, stability, among others, provoking uncertain panoramas that lead subjects to modes of expression of violence arising from disagreement with the impositions of the state and industry, having implement the monopoly of violence to contain the reactions of divergent groups. Of the authors with the greatest resonance on the subject of social disorder, is Durkheim. For his part, Parsons points to that distance between goals and means and the conflict it produces. Another approach is Spencer, who points out about conflicts between groups in the face of state repression. Weber explains the consolidation of the state apparatus through raising money and establishing its control devices. Finally, Bourdieu refers to the neoliberal forms that distance subjects from the opportunities and support the state could give, relegating him to his fate.

\section{PALABRAS CLAVE}

Apoderados del control social; desigualdad perpetuada; División del trabajo; Violencia colectiva.

\section{KEYWORDS}

Collective violence; division of labour; perpetuated inequality; social control controllers.

\section{INTRODUCCIÓN}

El Estado benefactor se distinguió por sus políticas públicas con postura intervencionista, abrazadora del colectivo, economía mixta, proteccionismo en igualdad de condiciones. Mientras que en el actual y trágico estado neoliberal, se sume en la tendencia de intervención mínima, marcando el individualismo, la economía dominante por los grupos minoritarios que acumulan la mayor riqueza, desigualdad al colectivo y sistemas irregulares de sistema laboral (Cantú Mendoza (2015).
Esto ha venido siendo observado por diversos autores de los cuales aquí se mencionan a cinco por ser los más revisados en la búsqueda de explicaciones sobre la dinámica sociedad-Estado-empresa. Estos previeron la tendencia cambiante en el mercado laboral y en las políticas públicas provenientes del Estado, el cual es notoria su cada vez más distante intervención en apoyo de regular, estabilizar o igualar las condiciones de desarrollo laboral en los ciudadanos.

Existen grupos que alcanzan la riqueza a través de la explotación de subgrupos necesitados con carencias y que urgen de medios para su sobrevivencia, la explotación laboral se ha venido marcando cada vez más, los esfuerzos del empleado son más requeridos a menor costo, sin recaudos que faciliten su armonía $\mathrm{y}$ estabilidad, conduciendo a la crisis colectiva, donde el régimen represivo empresarial es cada vez más notorio.

Por parte del Estado, libera el albedrío y la oportunidad al sector empresarial de explotar al empleado, mientras que regula en contra del sector de mano de obra. Las formas de evitar que la desigualdad siga avanzando junto con los problemas sociales que se están acrecentando es que el estado como tutor de los ciudadanos, intervenga de manera más igualitaria para todos, generando la plataforma legislativa e instrumentar la institucional, para la distribución adecuada de oportunidades, conduciendo a la estabilidad.

\section{EL DESORDEN SOCIAL COMO DETONANTE DE LA CRISIS VIOLENTA. DURKHEIM}

Comenzando con Durkheim, del cual se observa una presencia relevante en los textos que explican la criminalidad desde el enfoque anómico, aporta sus impresiones a través de sus estudios, destacando algunos problemas sociales derivados de la 
desorganización e incertidumbre (Ríos Patio, 2017) que se generan por los contrastes entre las necesidades sociales, los medios de obtención y el mecanismo generador de riqueza para satisfacer dichas necesidades, las consecuencias de tal desorganización se expresan mediante lo que él asignaba como anomia (Caycho Caja, 2018).

Se refiere a cambios vertiginosos donde las sociedades tradicionales no se adaptan con la misma celeridad, complicando la autoregulación, llevándolos al descontrol y conflicto interno para sumarse a las nuevas tendencias que los sistemas sociales dominantes impongan, principalmente cuando las expectativas generadas están apartadas de los criterios sociales reales, produciendo una ruptura, con lo cual, los sujetos interpretan como ausencia de reglas asimilables, por lo cual, chocan con sus sistemas y colapsan los individuos (Caycho Caja, 2018), vivenciado el nomos como lo trataban los teólogos medievales: Sin Dios, ni ley (Reyes Morris, 2008, p. 321).

Por otro lado, parte fundamental en su tesis, es la división del trabajo, al referirse a la especialización a la que avanzan o requieren los mercados, generando también desigualdad y clases obreras, la exagerada producción de mercancías para su comercialización, llevando a ritmos acelerados donde se busca producir más a menor costo, tanto material, y sobretodo humano, también llevando a la explotación, que genera en sí violencia (Maddaloni, 2016).

La división del trabajo y la especialización de los conocimientos, técnicas y funciones, colocan en cajas de actividades diferenciadoras de entre individuos, llevando a la desigualdad (Caycho Caja, 2018). "Ocasionando que el avance de formas inéditas de explotación del hombre, de segregación y de ataque a bienes jurídicos, se encuentre actualmente sin una salvaguardia eficaz; y que la humanidad haya involucionado a niveles de anomia (...), en un marco de enorme desigualdad" (Ríos Patio, 2016, p. 3).

En el actual, se ha consolidado que los individuos adquieren grados universitarios o títulos que dan un mejor posicionamiento social (París Pombo, 2012), se da un nombramiento que permite adquirir un capital simbólico, que conecta con otros de misma clase en un campo específico del saber, da autoridad, que les legitima, y diferencia, dando posiciones, clasificaciones, oportunidades, excluir, ser excluido, o aceptados (Cantú Mendoza, 2015).

A partir de lo anterior, se ha relacionado la desorganización social con consecuencias o motivos para la criminalidad, comportamientos antisociales, conductas desviadas, comportamientos autodestructivos, falta de cohesión social, de conciencia colectiva, de irregularidades entre el sentido colectivo y el individual, teniendo opuestos entre los valores colectivos nacionales y locales, priorizando las incertidumbres personales que no se adhieren ni se identifican con el resto del grupo, apartándose (Reyes Morris, 2008).

\section{CONFLICTO ENTRE METAS Y MEDIOS. PARSONS}

Se apunta a Parsons como una sintetizador y reorientador de los estudios de Durkheim, Weber, entre otros (Reyes Morris, 2008). Este concibe a la anomia como producto de las divergencias que ocurren entre las ya mencionadas exigencias o estándares sociales, en contra de las oportunidades para obtenerlos. Escondiendo un interés de control político e industrial, donde se plasman necesidades, obligaciones familiares, educativas, personales, de afecto (París Pombo, 2012). 
Contribuyendo con esto a más incertidumbre y pérdida de enfoque al observar que por más esfuerzo que se realice, los individuos no lograrán sus deseos impuestos o escondiéndose en aquellas necesidades, no ocurrirá algo similar al sueño americano, que se bascula en los pilares del esfuerzo y astucia (Caycho Caja, 2018), para lograr sus metas, sino por el contrario, toda energía carece de sentido (Reyes Morris, 2008), en ese orden, se produce la anomia.

Entiende el comportamiento adaptado del modo en que los actores sociales mantienen correspondencia con la norma, siguiendo los criterios establecidos, a lo que llama, institucionalización, por lo que persiste la conformidad y la referencia a un rol para el sistema social. Por el contrario, cuando los criterios normativos no han sido institucionalizados, ocurre la falta de estructuración del proceso de interacción (Caycho Caja, 2018), lo que conduce a una ruptura entre el régimen personal y el cultural.

\section{EL ESTADO COMO TUTOR DE LA REPRESIÓN, DESIGUALDAD Y VIOLENCIA: SPENCER, WEBER Y BOURDIEU}

En el orden del título del subtema, coinciden los tres últimos autores que se abordarán, Spencer, que puntualiza sobre los conflictos entre grupos ante la represión del Estado, Weber explica la consolidación del aparato del Estado; y Bourdieu, se refiere a las formas neoliberales que buscan eliminar el apoyo a la sociedad. Se concibe al Estado como el resultado de quitar a otros el poder individual, para darlo a un soberano (Gallego García, 2004), que a través de sus súbditos, ejerce acciones sobre los campos en que este estado se divide, teniendo el control del absoluto de las cosas.

Para lograr el efecto anterior, el Estado se ha especializado en actividades burocráticas que ampliamente otorga poderes simbólicos a los electos por los ciudadanos mediante su opinión anónima de elección, donde el nombramiento, da origen a el poder que se le confiere, que brinda y cede su palabra, acto, pensar a otros, para que este lo ejerza, teniendo responsabilidad individual y colectiva en las funciones que realizará. Esto también ha llevado a legitimar en las decisiones de ciertas personas, además del monopolio legítimo del poder (Gallego García, 2004), el de la violencia (como lo estudió Weber), donde los poderosos dominan al colectivo, conducen sus vidas, a su vez, estos se sujetan a otro dominio jerárquico dentro de su mismo territorio, o por instancias internacionales (proceso mundializador) que pretenden regular su actuar y diversos campos del estado (París Pombo, 2012).

Weber estudiaba cómo los Estados logran su legitimidad y poder a través de la burocracia especializada, pero en específico mediante los medios (Maddaloni, 2016) de acumulamiento de riqueza y financiamiento, como los son los impuestos, a través de los cuales, logran sus fines con un soporte monetario, y también mediante el sistema de justicia, que se emplea como ese sustituto de la violencia de los otros, tomada por el Estado para implementarla cuando no se logren arreglos pacíficos o amigables entre los individuos (Gallego García, 2004), pero también para aplicarlo ante rebeldes a los objetivos del Estado.

Por su parte, Bourdieu buscaba transformar el contexto social para conducirlo a un modo más equitativo, con sus estudios pudo develar las formas simbólicas en las que las desigualdades se perpetúan y se empodera aún más lo legitimo del Estado en cuya orientación neoliberal enmascara la desigualdad económica, social, política, siendo ya un mega actor que impone reglas arbitrarias, subjetivas, ocultando los intereses políticos (Ríos Patio, 2017). Con aquel poder, el Estado ha logrado arraigarse 
de modo casi inamovible, acercándose más a intereses particulares, y alejándose más de las necesidades de los sectores, provocándoles abandono, sufrimiento, por ejemplo, menciona la vivienda, la escuela, centros de salud, medios de comunicación (París Pombo, 2012). Al haber sacrificado y dejado en modo precario los sectores anteriores, se tiene en contraparte, el aumento de conflictos, una más marcada desigualdad, agresividad, delincuencia, uso de drogas "Las políticas neoliberales están correlacionadas con, e incluso son factores causales del aumento de una violencia" (París Pombo, 2012, p. 29).

Spencer "observa que una presión mayor sobre los recursos disponibles implica un aumento de la competencia entre los individuos y los grupos sociales" (Maddaloni, 2016, p. 116). Refiere un modo positivo para la salida de esa tensión, como la innovación en el aumento de los recursos a través de las sociedades industriales, pero también reconoce que puede generar conflicto, violencia y lucha entre grupos, a lo cual, el Estado, con el poder legitimado y socialmente otorgado, instrumenta los medios para ejercer el control sobre las masas. Se genera un clima de miedo, desesperación y que engendra actos violentos, antisociales, criminales (Maddaloni, 2016).

\section{CONCLUSIONES}

La organización de la vida y su administración tiene pretensiones de acabar con los conflictos y buscar la paz, en un mismo espacio común, mediante reglas de convivencia que garanticen la armonía de los grupos, sin estar bajo miedo o amenaza, pero este efecto, se logra a través de ejercer violencia contra quienes se oponen a guardar el orden social, a través del aparato del Estado, que ha abusado de su función reguladora para llevarla a modos de control total sin que se le pueda contrariar, puesto que aplica leyes, fuerza y órganos de sumisión, y donde el que oponga resistencia, puede ser considerado ejecutor de un acto de criminalidad. Retomando y cerrando con Bourdieu, este deja ver que los investigadores deben recuperar la voz, ser interlocutores de los actores sociales que aunque situados ante el Estado, son excluidos, oprimidos y explotados.

\section{FUENTES DE INFORMACIÓN}

\section{Fuentes bibliográficas}

Cantú Mendoza, R. (2015). El Cambio Universitario en México: Un abordaje desde la Perspectiva de la Calidad. Estudio de un Caso Exitoso: La Facultad de Filosofía y Letras de la UANL. San Nicolás de los Garza: Facultad de Filosofía y Letras, Universidad Autónoma de Nuevo León.

\section{Fuentes electrónicas}

Caycho Caja, A. (2018). Sociopsicología de la anomia. Revista de Investigación en Psicología, 21(2), 285-300. Recuperado de https://revistasinvestigacion.unmsm.edu.pe /index.php/psico/article/download/15828/1 3556/

Gallego García, G.M. (2004). Sobre el monopolio legítimo de la violencia. Revista de Derecho Penal, (14), 127-152. Recuperado de https://dialnet.unirioja.es/descarga/articulo/ 3823123.pdf

Maddaloni, D. (2016). Para una sociología de la violencia. América Latina en perspectivas comparada. Cultura Latinoam, 24(2), 110-128. Recuperado de https://editorial.ucatolica.edu.co/ojsucatoli ca/revistas_ucatolica/index.php/RevClat/ar ticle/viewFile/1592/1470

Mills, C.W. (1961). La Imaginación Sociológica. Ciudad de México: Fondo de Cultura Económica. Recuperado de https://es.scribd.com/document/351826461 
/Wright-Mills-Charles-La-imaginacionsociologica-pdf\#

París Pombo, M.D. (2012). La fabricación de armas para una revolución simbólica. Pierre Bourdieu y la sociología de la dominación. Sociológica, (77), 7-34. Recuperado de http://www.scielo.org.mx/pdf/soc/v27n77/ v27n77a1.pdf

Reyes Morris, V. (2008). Anomia y criminalidad: Un recorrido a través del desarrollo conceptual del término Anomia. Revista Criminalidad, 50(1), 319-332. Recuperado de http://www.scielo.org.co/pdf/crim/v50n1/v 50n1a09.pdf

Ríos Patio, G. (2017). La Fractura de la Política Criminológica en la Constitución y la Realidad Nacional, 1-66. Centro de Estudios de Criminología, Universidad de San Martín de Porres. Recuperado de: https://biblat.unam.mx/hevila/Revistainclu siones/2016/vol3/no2/11.pdf

Ríos Patio, G. (2016). El lado poco conocido de la globalización en la grave afectación a los derechos humanos: Un enfoque criminológico para prevenir $\mathrm{y}$ reducir la criminalidad organizada a nivel mundial, 2(3), 1-22. Revista Inclusiones. Revista de Humanidades y Ciencias Sociales. Recuperado de https://biblat.unam.mx/hevila/Revistainclu siones/2016/vol3/no2/11.pdf 